\title{
Professional Task-Based Curriculum Development for Distance Education Practitioners at Master's Level: A Design-Based Research ${ }^{1}$
}

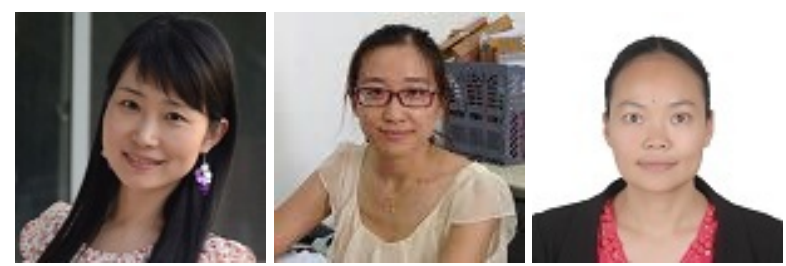

Xiaoying Feng ${ }^{1}$, Guangxin $\mathrm{Lu}^{1}$, and Zhihong $\mathrm{YaO}^{2}$

${ }^{1}$ Beijing Normal University, China, ${ }^{2}$ University of Central Committee of C.P.C, China

\begin{abstract}
Curriculum development for distance education (DE) practitioners is more and more focusing on practical requirements and competence development. Delphi and DACUM methods have been used at some universities. However, in the competency-based development area, these methods have been taken over by professional-task-based development in the last decade, which has not been applied in the open and distance education area so far. Is the professional-task-based curriculum development approach suitable for open and distance education? This study aims to develop a Master Degree curriculum for DE practitioners in China based on professional tasks. Design-based research (DBR) was used and two cycles of DBR were conducted. Interviews and observations were used to collect data. In the first round of DBR, the authors find that professional-task-based development is feasible and could direct more closely to practical requirements of competencies, and that meanwhile, this approach has some disadvantages and limitations. In the second round of DBR, the approach was revised and results showed that the revised approach was much more suitable and reasonable for DE practitioners. Results of this study include: 1) professional-task based curricula for DE practitioners in China; 2) a curriculum development approach for open and distance education revised from professional-task-based development.
\end{abstract}

Keywords: Curriculum development; professional tasks; competency-based education

\footnotetext{
${ }^{1}$ This study is funded by the Key Project of Beijing Education Sciences Planning titled "Development of Curriculum Development Approach for Adult Distance Learners” (Project No.: AJA11173).
} 


\section{Introduction}

China has a huge DE market and along with this is a huge team of more than 300,000 practitioners and 30,000 teachers in the DE field in China. Most of these practitioners have had a Bachelor's Degree but have very little idea about the principles and pedagogy of DE. Hence, professional training is widely and urgently needed in the DE field in China. Further education on $\mathrm{DE}$ at the Master's level is most welcomed by practitioners as a helpful way for their professional development, especially in on-the-job DE.

Obviously, further education for these practitioners should be competency-oriented. It is wellknown that competency-based education (CBE) is student centered and students are more satisfied and competent, better understand the goals of their training, and take more responsibility for their own learning (Frank et al., 2010; Albanese et al., 2010; McLean, \& Braden, 2006). However, as Hatcher emphasized, the biggest challenge of CBE lies in creating and implementing a CBE program (Hatcher, et al., 2013).

Some pilot studies have been done to develop competency-based curriculum for MDDE by means of the Delphi method or/ and the DACUM method (Thach \& Murphy, 1995; Williams, 2000; Egan \&Akdere, 2005; Ally \& Coldeway, 1999).

DACUM was adopted from the vocational education field and used to be a typical approach for competency-based curriculum development two decades before (Anderson, A., 1994; Anderson, G., 1994; Mndebele, 1997; Percoco, 1998). However, in the last decade, shortcomings of this approach have been recognized and another approach—professional tasks development (PTD) has evolved from DACUM and has become the dominating approach for competency-based curriculum development, mainly in the vocational/industry education field and CBE. The PTD approach is believed to be more competency-targeted, more efficient to develop practice-needed competencies, and more reasonable to combine knowledge study with competency development (Zhao, 2009). Is the PTD approach viable and suitable for curriculum development for DE practitioners at the Master's level? And, furthermore, is it possible to generate it into a competency-oriented curriculum development approach suitable for the DE field?

\section{Purpose of the Study}

According to Plomp (2007), the goal of educational design research is twofold: one is practicedriven and the other is theory-oriented. Following a typical design-based research (DBR) process, this study has twofold purposes. The practice-driven goal is to develop a competency-based curriculum for DE practitioners at the Master's level; and the theory-oriented goal is to develop a competency-based curriculum development approach for open and distance education using a revised PTD technique.

This work is licensed under a Creative Commons Attribution 4.0 International License. 


\section{Conceptual Framework}

CBE has been the leading paradigm for innovation in higher education, both at the system level and at the level of learning environments (Biemans et al., 2004). An important reason is the expectation held by many stakeholders that the gap between the labor market and education can (and will) be reduced through CBE (Biemans et al., 2004; Mulder, 2004). As the basis of CBE, competency-based curriculum development aims to derive a curriculum from an analysis of a job/ occupation in modern society. Ever since the origins of CBE in the 1960s, approaches for competency-based curriculum development could be classified into two categories, one is roleoriented, the other is task-oriented.

\section{Role-Oriented Competency Development}

Role-oriented competency development aims to examine the human skills and abilities needed to perform the job successfully. In a role-oriented competency development, a competency framework or competency model is usually drawn for roles of the occupation, which can serve as a curriculum guide for an educational program (Sherrill \& Keels-Williams, 2005). Role-oriented development has been dominating competency-based curriculum development in last century. The typical methods for role-oriented development are the Delphi method and the DACUM method.

Delphi method is a systematic and structured approach of collecting knowledge and generating consensus of expert opinion through the administration of a series of repeated questionnaires alternated with controlled opinion feedback (Ziglio, 1996; Polit \& Beck, 2004). Delphi method is particular useful when the available information is incomplete (Bulger \& Housner, 2007) or when the problem does not lend itself to precise analytical techniques (Rice, 2009). In this case, although the existence of consensus does not mean the answers are correct, the Delphi method can provide importance and expert insights into a particular topic or area (Shell, 2006).

DACUM is an acronym for "Developing a Curriculum" and has been used to determine competencies that must be performed by persons in a given occupational area (Linton et al., 2011). DACUM process engages a panel of experts in structured brainstorming workshops to generate a profile of skills and duties for a specific occupation, which can be used as the basis for creating educational programs (Sherrill and Keels-Williams, 2005; Kang, et al., 2012; Linton, et al., 2011).

The Delphi and DACUM methods have several advantages. Knowledge of experts could be collected for curriculum development. And the end product of the Delphi or DACUM process is a competency model which could give a clear profile of competencies and skills to be included in courses. However, some weaknesses and risks of role-oriented development include (Cate \& Scheele, 2007; Tanner, 2001; Mulder, 2003; Biemans et al., 2004): 1) lack of clear guidelines to

This work is licensed under a Creative Commons Attribution 4.0 International License. 
translate the competencies into the practice of teaching; 2) lack of clear guidelines to connect a competency model with the work environment; and 3) lack of a clear route map to make the competency model developmental, that is, to define different competency frameworks for different program levels/ types and to progress from one type of program to another.

\section{Task-Oriented Competency Development}

Ever since 2000s, task-oriented development has been advocated as a more holistic approach to overcome the risks of role-oriented development. In task-oriented development, a wider definition of competency was given and competency is regarded as the integrated abilities required to cope with complex tasks (Boreham, 2002a; Biemans et al., 2004; Heusden, 2004). Hence task-oriented competency development focuses on the actual tasks involved in an occupation and work-process knowledge in the tasks. In a task-oriented development, the critical tasks would usually be recognized and detailed task statements would be given, which would serve as the concept framework of the curriculum. Task-oriented development has been adopted in the fields of vocational education, engineer education and psychology education. The typical methods for task-oriented development are the Professional Task Development (PTD) method and the Entrusted Professional Activities (EPAs) method.

The PTD method is a methodology generated from vocational education in Germany. In the PTD process, work process knowledge is collected from a panel of practical experts in the form of workshops. Experts are asked to reflect on the practice and to identify the career development stages of a certain occupation and critical professional tasks that constitute the work process. The curriculum is then documented as a set of learning fields that mirror the critical professional tasks (Boreham, 2004).

The EPA method is the term of task-oriented development in the area of medical education and is regarded as having the advantage of linking the competency domains and sub-competencies directly to clinical activities of the specialty (Cate \& Scheele, 2007; Cate, 2005; Powell, 2011).

Task-oriented development encourages the students to accomplish tasks with a practical setting as a pointer to the relevant theory. Thus, task-oriented development is believed to be a better vehicle for integrating theory and practice (O’Halloran, 2001).

\section{Distance Education Curriculum Development Framework for Adults}

Existing studies and practice of competency-based curriculum development for MDDE have been role-oriented, this study would try a task-oriented development. As a typical method of taskoriented development, PTD emphasizes learning with real tasks in real circumstances, guided by the constructivism. This approach also follows the theory of social development psychology which believes that each developmental stage has its critical tasks and that humans develop via implementing these tasks successfully.The classical process of PTD includes three steps (Boreham, 2004). Step 1 is 'Vocational Analysis', in which a brief understanding and profile of the

This work is licensed under a Creative Commons Attribution 4.0 International License. 
industry is drawn. Step 2 is 'Professional Tasks Analysis' or 'Activity Fields Analysis', in which vocational development stages and critical professional tasks in each stage are recognized and investigated in an activity field via practical expert workshops. Step 3 is called 'Learning Fields Analysis', in which the curriculum is documented as a set of learning fields that mirrors the activity fields constituting the work process.

Based on the classical PTD process, and taking distant learner analysis and subject needs into account, a draft version of the Distance Education Curriculum Development for Adults (DECDA) is proposed and used as the design framework in this study (Figure 1).

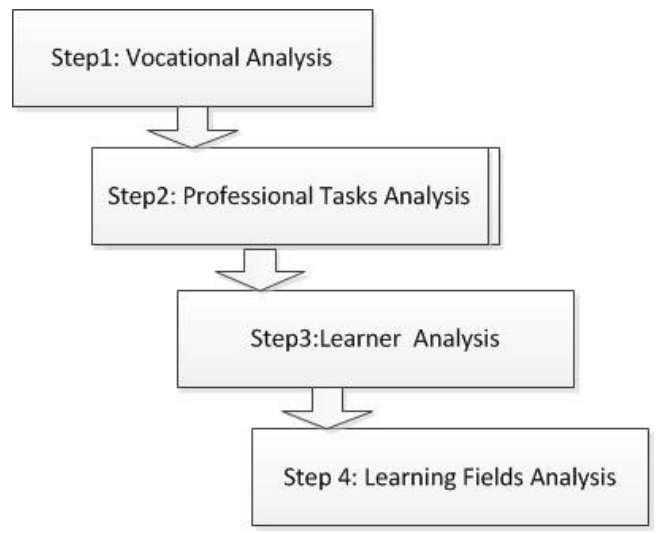

Figure 1. Proposed framework of the professional-task-based curriculum development.

\section{Methodology}

\section{Methods}

Design-based research was selected as the methodology of this study. Design-based research has been seen as a new research methodology for educational research in the last decade, which blends empirical educational research with the theory-driven design of learning environments (The Design-based Research Collective, 2003). Anderson and Shattuck (2012) characterized DBR as being situated in a real educational context, focusing on the design and testing of a significant intervention, use of mixed methods, involving multiple iterations, involving a collaborative partnership between researchers and practitioners, yielding design-principles, and with a practical impact on practice. It's especially emphasized by many researchers that DBR seeks two goals of advancing theoretical understanding and benefiting practice (Anderson and Shattuck, 2012; McKenney and Reeves, 2013; Teras and Herrington, 2014; The Design-based Research Collective, 2003). In this study, the intervention is the professional-task-based competency curriculum development. This study seeks theoretical understanding of a curriculum development approach for distance education, and benefiting practice of competency-based

This work is licensed under a $\underline{\text { Creative Commons Attribution } 4.0 \text { International License. }}$ 
MDDE curriculum development. Two iterative cycles of DBR were conducted. Observational method, interviews and expert workshops were used to collect data.

\section{Procedure}

Firstly, a proposed framework for curriculum development was put forward via literature review.

Then, the first cycle of DBR was conducted. The authors sought to develop the curriculum for DE Practitioners at Master's Level under the guidance of the proposed framework. During the course, observational methods and interviews were used to collect data. Some conclusions and implications were considered and the framework was refined.

Thirdly, the second cycle of DBR was conducted. This time the curriculum was re-developed under the guidance of the revised development framework. Evaluation data were collected via observations and interviews.

\section{Participants}

The expert workshop is one of the main methods in this study. According to the PTD approach, a panel of 10-15 qualified experts is needed. In this study, 10 experts were invited to the workshop panel. All of them had worked in the DE field for 8-15 years from novice to expert. Ten experts were selected from three typical DE systems in China (as shown in Table 1). The experts' role backgrounds were also considered (as shown in Table 2). The expert panel covered the main role area of DE: learner support, course design \& development, teaching \& tutoring, technical support $\&$ development, management \& quality assurance. In each role area, at least three experts had such role backgrounds. All these 10 experts engaged in 2 cycles of DBR process.

Table 1

Expert Sampling from Different DE Systems

\begin{tabular}{l|l}
\hline DE system & Number of experts \\
\hline Open universities & 3 \\
Online colleges & 4 \\
E-learning companies & 3 \\
\hline
\end{tabular}

This work is licensed under a Creative Commons Attribution 4.0 International License. 
Table 2

Experts' Role Backgrounds

\begin{tabular}{|c|c|c|c|c|c|}
\hline Expert & Learner support & $\begin{array}{l}\text { Course } \\
\text { design \& } \\
\text { development }\end{array}$ & $\begin{array}{l}\text { Teaching \& } \\
\text { tutoring }\end{array}$ & $\begin{array}{l}\text { Technical } \\
\text { support \& } \\
\text { development }\end{array}$ & $\begin{array}{l}\text { Management } \\
\text { \& quality } \\
\text { assurance }\end{array}$ \\
\hline P 1 & $\sqrt{ }$ & $\sqrt{ }$ & & & $\sqrt{ }$ \\
\hline $\mathrm{P} 2$ & & $\sqrt{ }$ & & $\sqrt{ }$ & $\sqrt{ }$ \\
\hline P 3 & & $\sqrt{ }$ & $\sqrt{ }$ & & \\
\hline $\mathrm{P} 4$ & & & & $\sqrt{ }$ & $\sqrt{ }$ \\
\hline P 5 & & $\sqrt{ }$ & $\sqrt{ }$ & & $\sqrt{ }$ \\
\hline P 6 & $\sqrt{ }$ & & & & \\
\hline P 7 & & $\sqrt{ }$ & $\sqrt{ }$ & & $\sqrt{ }$ \\
\hline P 8 & & $\sqrt{ }$ & & & $\sqrt{ }$ \\
\hline P 9 & & $\sqrt{ }$ & & & \\
\hline P 10 & $\sqrt{ }$ & $\sqrt{ }$ & & $\sqrt{ }$ & $\sqrt{ }$ \\
\hline In total & 3 & 8 & 3 & 3 & 7 \\
\hline
\end{tabular}

\section{Data Analysis}

The interview and observation data were analyzed focusing on the following questions: 1) Is the PTD process feasible and suitable for MDDE curriculum development? 2) What kinds of difficulties or problems occurred during the course of development? 3) Has the developed MDDE curriculum met our objectives: that is, has it met the requirements of DE practice, and is it suitable for needs of our target students - DE practitioners?

Data analysis results were sent back to every participant for a check to ensure the validity of the data. 


\section{First Cycle of DBR}

\section{Results}

Q1: Is the PTD process feasible and suitable for MDDE curriculum development?

During the whole course of development, the development process proceeded smoothly in general. All the participants, including interviewees, practical experts and academic staff, showed great interest and positive attitudes regarding the development approach.

The experts used terms such as "refreshing" and "wonderful" to describe their feelings about the development approach.

'It's a really refreshing approach. It's a wonderful experience for me to rethink my career history and to summarize the professional tasks during my career development. That's really great!' (P3, P6)

Thank you for offering us such an opportunity to rethink my career history. That's a refreshing and wonderful feeling for me!' $(\mathrm{P} 1, \mathrm{P} 10)$

The experts compared the development approach with existing approaches in their institutions and expressed positive attitudes and optimistic expectations about it. They thought it feasible and close to practical requirements in this field.

'I'm glad to see that my career history has much in common with peers in other institutions. I think these professional tasks are typical for DE practitioners. And obviously curricula based on the professional tasks would be much more close to practical requirements in this field. I look forward to adopting this approach in curriculum development in my college in future.' (P7)

'My college has realized the importance of competency-based curriculum/ course development for our distance learners. We used it to develop a competency-based curriculum for a nursing

This work is licensed under a Creative Commons Attribution 4.0 International License. 
specialty via a DACUM approach last year. However, we found it too complicated to develop a series of courses after defining a capability model of 60 capabilities. After that, we were still not sure how far our courses dealt with the practical requirements. Obviously, professional-task-based development is much more reasonable and workable. Professional tasks would be a much more helpful bridge to connect the courses with the professional development of learners.' (P4)

Q2: What kinds of difficulties or problems occurred during the course of development?

Observations showed that confusions and differences occurred among the participants. Confusions and differences were mainly about the meaning of some professional tasks, which created problems in sorting them out. Sometimes the experts used different names for professional tasks which turned to be the same task. On the other hand, some professional tasks were given the same name by experts while having different meanings, such as "course development" and "learner support". How an expert defines a professional task appeared to be affected by his/ her own role or position.

"I could not understand well some professional tasks listed by other experts. For example, does 'course development' refer to the development of a single course or the curriculum development of a program?" (P3)

"I'm not sure whether we are talking about the same thing......'Course development' is mentioned by every expert. From the point view of an instructional designer, I listed 'course development' as the instructional design of an online course; from the point view of a technician, Mr. Shen focused it on the production of course materials; whilst, from the point view of a project manager, Dr. Wu referred it to the whole process of course design and development; and Ms. Du took it as the curriculum development for a program..... That's really confusing." (P2)

Q3: Has the developed MDDE curriculum met our objectives: that is, has it met the requirements of $\mathrm{DE}$ practice, and is it suitable for needs of our target students - $\mathrm{DE}$ practitioners?

This work is licensed under a Creative Commons Attribution 4.0 International License. 
Just as in Q1, the experts in being interviewed all stated that the developed MDDE curriculum could meet the capability requirements of DE practice fairly well. However, the experts also pointed out some shortcomings. Several of them mentioned that not all the professional tasks are suitable for the degree and our target learners. Prior knowledge and capabilities of target learners should be taken into account when deciding which tasks should be adopted into the curriculum.

"The MDDE curriculum was mainly developed from the 17 professional tasks identified by the practical experts. These professional tasks obviously reflect the capability requirements of practice. However, not all of these professional tasks are suitable for Master Degree study, such as 'enrollment and recruitment'." (P5)

"Since our target learners are DE practitioners, they have had some existing knowledge and experience on distance education. For example, they are already capable of most professional tasks in Stage 1, since they are not 'new hand' yet. Therefore, it may be not suitable to take these tasks into account in our curriculum." (P9)

Some experts also expressed their doubts about selection of professional tasks.

"There were too many typical tasks. Some of them were similar to each other, whilst some have different meaning even though they have similar names... However, different roles are not taken into account. Therefore, in the final version of the professional tasks, tasks of different roles were merged into one single professional task. Obviously, this caused difficulties and confusions when we tried to transfer these professional tasks into a professional course... So I think it's difficult to sort out a series of professional tasks without taking roles into account." (P7)

"Obviously this is a fairly good development approach and we have done a great work! However, it's a pity that different roles of DE practitioners were not taken into account in this approach and our final curriculum. We have different roles in this field and different roles have different tasks, anyway." (P3)

This work is licensed under a Creative Commons Attribution 4.0 International License. 


\section{Findings and Implications}

From the results of observations and interviews, some findings and implications were derived.

1. It is feasible and viable to get an overview of the DE industry and its typical work, roles and needs via interviews in Step 1 'Occupation Analysis'.

2. The development focused on the needs of the DE industry and tried to focus the curriculum on the industry needs directly via 'Vocational Analysis' and 'Professional Tasks Analysis'. It seemed that the development did dig out the needs of the DE industry for practitioners and could give a closer connection between the MDDE curriculum and the industry needs.

3. During the course of the development, advantages of PTD could be recognized. First, it paid attention to the career development process of practitioners, which assists in the structure of the curriculum. It also makes it possible to develop different levels of curricula to meet different student needs. Secondly, professional courses are derived from the professional tasks, and designed following the theories of situated learning. Thirdly, PTC is relatively easier to understand and operate.

4. However, PTD is only suitable for single-role industry and programs, since different roles are not taken into account during the course of development.

5. PTD takes the hypothesis that the learners have no prior knowledge or experience in this field at all, which is obviously not the case in DE. More factors should be taken into account, such as the prior knowledge and experience of target learners, needs of target learners, and different levels of program.

\section{Second Cycle of DBR}

\section{Redesign Steps}

In the first DBR cycle, it was found that PTD is a reasonable and feasible approach for developing competency-based curricula. However, the approach has some limitations when applied to the DE field. So in the second cycle of DBR, some revisions were made to the traditional PTD approach.

Firstly, the concept of roles was taken into account when applying professional tasks analysis, so as to compensate the weakness of the traditional PTD approach in multi-role industry. As Egan \& Akdere (2005) indicated, roles and competencies are interrelated. Hence key roles in the industry related with the program should be taken into account in curriculum development. A role can be defined as a set of expectations defining the appropriate behaviors and expectations of an occupant of one position in relation to those in other positions (J ohnson and Johnson, 1994). Hence, in the practical expert workshop, professional tasks were recognized and sorted according to not only career development stages but also different roles in the DE field. Hence, the key roles in this field relevant to this program were recognized in Step 1 as 'occupation analyses'.

This work is licensed under a Creative Commons Attribution 4.0 International License. 
Secondly, learner analyses' was emphasized in Step 2, so as to give a target-group profile of learners for professional task analyses. Prior knowledge and competence of learners, expectations and needs of learners, and so on, were collected. The target group profile was used to decide which professional tasks would be suitable for target learners and therefore would be adopted in the curriculum.

In the second cycle of DBR, the MDDE curricula were re-developed following the revised process. Step 1 was still 'Vocational Analysis' as in the first cycle, and four key roles in DE relevant to this program were recognized: 'teaching staff', 'instruction designer', learner supporter', and 'technician'. In Step 2 (Learner Analysis), a target group profile was obtained via interviews. In Step 3 (Professional Task Analysis), the practical expert workshop was still used. A matrix of professional tasks was formed by considering both career development stages and key roles (as shown in Table 3). Some professional tasks were identified as shared by all key roles. Target group profile and level of program were both considered when selecting professional tasks.

Table 3

Matrix of Key Roles and Development Stages in DE

\begin{tabular}{|c|c|c|c|c|}
\hline Key role & $\begin{array}{l}\text { Stage 1: New } \\
\text { Hand }\end{array}$ & $\begin{array}{l}\text { Stage 2: } \\
\text { Independent } \\
\text { Worker }\end{array}$ & $\begin{array}{l}\text { Stage 3: } \\
\text { Team/ Project } \\
\text { Leader }\end{array}$ & $\begin{array}{l}\text { Stage 4: } \\
\text { Department } \\
\text { Manager }\end{array}$ \\
\hline $\begin{array}{l}\text { Common } \\
\text { professional } \\
\text { tasks for all } \\
\text { roles }\end{array}$ & $\begin{array}{l}\text { Induction } \\
\text { Training; } \\
\text { Application of } \\
\text { DE Platforms }\end{array}$ & $\begin{array}{l}\text { Technology } \\
\text { Application in DE }\end{array}$ & $\begin{array}{l}\text { Project } \\
\text { Planning and } \\
\text { Management in } \\
\text { ODL }\end{array}$ & $\begin{array}{l}\text { Implementing } \\
\text { and } \\
\text { Management of } \\
\text { DE Systems }\end{array}$ \\
\hline $\begin{array}{l}\text { Instructional } \\
\text { designer }\end{array}$ & $\begin{array}{l}\text { Design and } \\
\text { Development of } \\
\text { Media } \\
\text { resources in } \\
\text { ODL }\end{array}$ & $\begin{array}{l}\text { Instructional } \\
\text { Design in DE }\end{array}$ & $\begin{array}{l}\text { Course } \\
\text { Development } \\
\text { Management in } \\
\text { DE }\end{array}$ & $\begin{array}{l}\text { Program } \\
\text { Curriculum } \\
\text { Development in } \\
\text { DE }\end{array}$ \\
\hline Technician & $\begin{array}{l}\text { Technical } \\
\text { Support for DE } \\
\text { Systems }\end{array}$ & $\begin{array}{l}\text { Software } \\
\text { Development in } \\
\text { DE }\end{array}$ & $\begin{array}{l}\text { Platform } \\
\text { Development in } \\
\text { DE }\end{array}$ & \\
\hline $\begin{array}{l}\text { Learner } \\
\text { supporter }\end{array}$ & & $\begin{array}{l}\text { Learner Support in } \\
\text { DE }\end{array}$ & & $\begin{array}{l}\text { Design and } \\
\text { Management of } \\
\text { the Learner } \\
\text { Support System } \\
\text { in DE }\end{array}$ \\
\hline Teacher & $\begin{array}{l}\text { Design and } \\
\text { Development of } \\
\text { Media } \\
\text { resources in } \\
\text { ODL }\end{array}$ & $\begin{array}{l}\text { Tutoring in DE; } \\
\text { Instructional } \\
\text { Design in DE }\end{array}$ & & $\begin{array}{l}\text { Program } \\
\text { Curriculum } \\
\text { Development in } \\
\text { DE }\end{array}$ \\
\hline
\end{tabular}


In Step 4 (Curriculum Planning), the professional tasks were transferred to professional courses, and theoretical courses were decided via a workshop of academic staff and academic experts.

\section{Results}

In the second cycle, interviews and observations were used to collect data to study the effectiveness of the revised development approach and its outcomes.

Q1: Is the revised development process feasible and suitable for MDDE curriculum development?

The revised development approach was highly regarded by the experts. All the experts expressed that it is much more reasonable and feasible after taking the roles, level of program, and target group profile into account.

"The revised approach is very good! Level of program and target group profile helped to determine the start-point of the program curriculum, which makes the curriculum development much more reasonable and suitable for the MDDE program." (P1)

"Owing to the fast changing development of society, existing courses and programs will not meet all new needs. This (development approach) is very practical and urgently needed. There's no gap between our courses and the needs of the industry -- we'll give you what you need directly." (P6)

"I like the matrix! From the matrix, we can see clearly the career development stages and professional tasks of every key role. It's fairly reasonable to plan different specialization courses according to different roles."(P7)

“It's really good, and urgently needed for the field of distance education. You should develop it into a whole set of development processes and approaches, so that all the distance education institutions could use it to develop their major curricula." (P9)

“It's a really good idea to develop curricula based on professional tasks. I wish we had used this approach to develop our Nursing Major curriculum." (P4) 
Q2: Has the developed MDDE curriculum reached our objectives: that is, has it met the requirements of $\mathrm{DE}$ practice, and is it suitable for needs of our target students - DE practitioners?

All experts showed their satisfaction with the second version of the curriculum.

"Many staff members at CRTVU (China Radio \& TV University) have had work experience in distance education. But they need theoretical approaches and methods to guide and improve their work. The MDDE courses could provide them with a systematic study connecting theory methods with professional tasks, which is brilliant for them!" (P1)

"I like this version of the MDDE curriculum. Especially, a student could select courses suitable for his/her role and could even see his/her future career route and relevant competencerequirements of his/ her role. That's important for them!" (P7)

Q3: What kind of difficulties or problems occurred during the course of development? Are there any suggestions about the approach?

During the second cycle of DBR, no obvious difficulties or problems were found via interviews and observations, except that it is still difficult for practitioner experts to understand the concept of 'professional task' at first. In the interviews, some suggestions were given by the experts. Two experts mentioned the importance of the presider and pointed out that the presider should not only master the PTD approach, but also have a relevant background of this field (P5, P7).

\section{Findings and Implications}

From the results of interviews and observations, some findings and implications were derived.

1. The revised approach was more effective and more reasonable. Most importantly, it made up for shortcomings in the traditional PTD approach, and is feasible not only for single-role but also multi-role fields.

2. The presider plays an important role in the workshop. He/ she needs to have a background in the field, or to have engaged in Step 1 and Step 2, in order to be aware of the discipline and the target learners.

3. Flexible learning needs should be considered for adult learners. Hence, a flexible curriculum structure should be designed for DE in Step 4.

4. Development of each course can be based on professional tasks, taking generative course design and professional ethics into account.

This work is licensed under a $\underline{\text { Creative Commons Attribution } 4.0 \text { International License. }}$ 


\section{Discussion}

\section{Revised Version of the DECDA}

After two cycles of DBR, a revised version of the DECDA model is defined as the Distance Education Curriculum Development for Adults (shown as Figure 2). This DECDA model is developed and revised from the PTD approach and is designed specifically for DE.
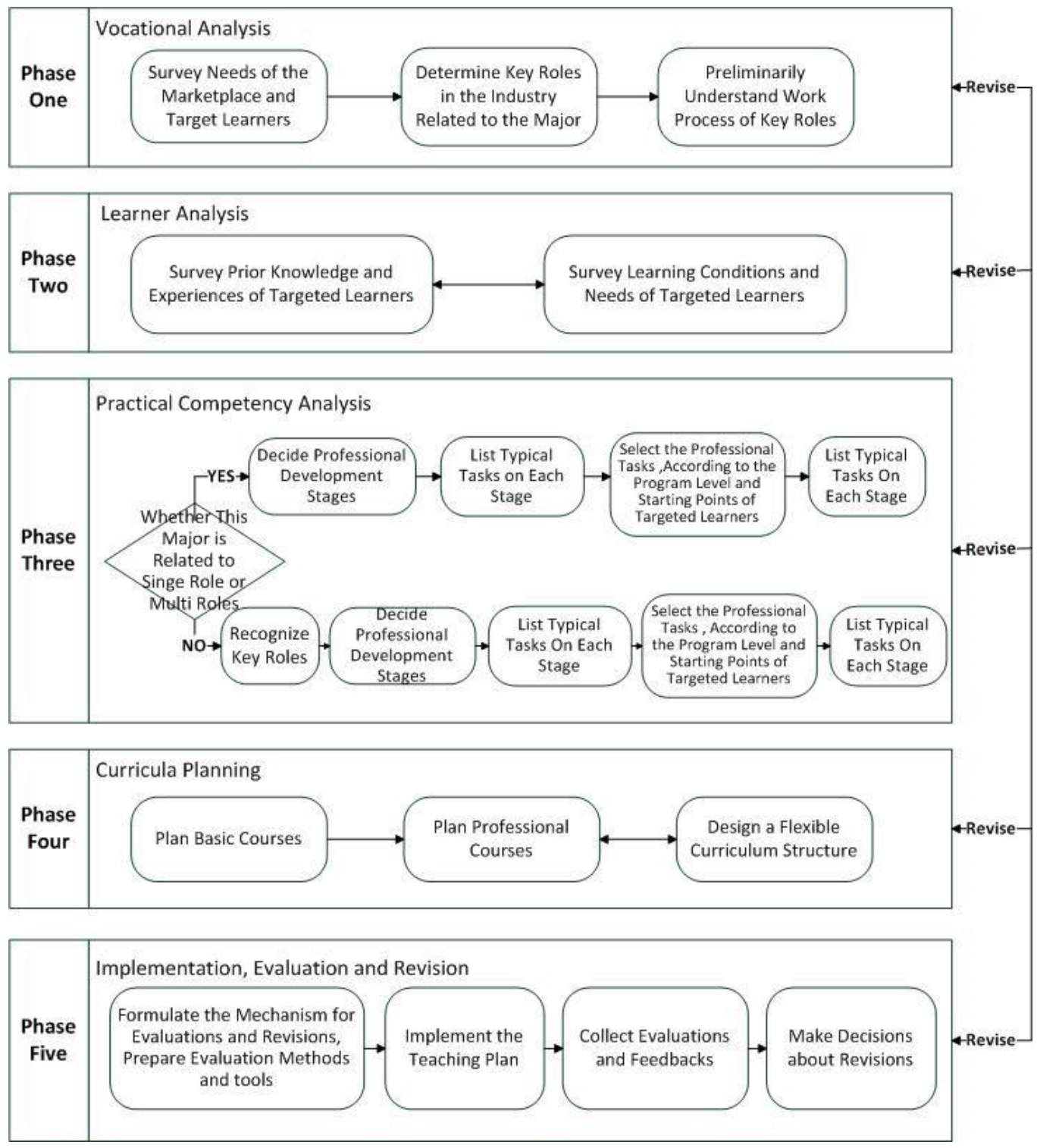

Figure 2. Revised version of the DECDA model.

This work is licensed under a $\underline{\text { Creative Commons Attribution } 4.0 \text { International License. }}$ 


\section{Phase one: Vocational analysis.}

The first step is Vocational Analysis, which includes three tasks: 1) to survey the needs of the marketplace and targeted learners; 2 ) to determine key roles in the industry related to the major; and 3) to gain a preliminary understanding of the work process of key roles and to identify practical experts to be invited to phase 3. In this phase, the interview method is the most useful vocational analysis approach. It can be used in conjunction with observation, questionnaire survey, and/ or literature review.

\section{Phase two: Learner analysis.}

Learner Analysis aims to get a profile of the target group, including 1) their prior knowledge and experiences and 2) their learning conditions and needs. The prior knowledge and experiences of the target group will help to understand and determine the curriculum development starting point, whilst the learning conditions and needs help to design the learning objectives, content and the curriculum organization. Interviews and questionnaires can be used in the Learner Analysis phase.

\section{Phase three: Practical competency analysis.}

Practical competency analysis is the core of curriculum development. A revised PTD approach is used in this phase. Firstly, it is necessary to judge whether the major is related to single or multiple roles. The main steps for practical competence analysis conclude:

1) defining the professional development stages of each role, usually divided into 3 to 5 stages according to its process and laws from novice to expert;

2) listing typical tasks on each stage of the professional development for each role;

3) recognizing critical professional tasks among these typical tasks;

4) selecting the professional tasks required by the program, according to the program level and starting points of target learners; and

5) describing the selected professional tasks, including names, objectives, requirements for competencies, tools, environment, processes, and so on. Each professional task will usually be a blueprint of a professional course.

The practical competence analysis is typically done via a practical expert workshop. Usually the expert panel comprises 10 to 15 qualified practical experts. The success of the analysis depends greatly on the selection of experts. A good host for the workshop is also important, who needs to understand not only the PTD approach but also the profile of the subject and target learners.

This work is licensed under a Creative Commons Attribution 4.0 International License. 


\section{Phase four: Curriculum planning.}

In phase 4, the curriculum is documented as a set of learning fields that mirror the activity fields of professional tasks. At the same time, subject needs and basic theoretical courses will also be considered. The main work of this phase includes: 1) basic course planning; 2) professional course planning; 3 ) design of a flexible curriculum structure. The descriptions of professional tasks in phase 3 are the blueprint of the planning, which will be mirrored by the objectives, content, process, context, and so on. Project-based learning or problem-based learning will be the typical teaching strategy of the course.

\section{Phase five: Implementation, evaluation and revision.}

The last phase is the implementation, evaluation and revision of the curriculum. With frequent knowledge updates, DE connects closely with social practical needs, since distance learners are usually in-service adults. In this situation, DE institutions should formulate a mechanism which can evaluate and revise the specialty establishment and curriculum periodically, in order to meet the dynamic needs of social practice and learners. This phase includes: 1) formulating the mechanism for evaluations and revisions, and preparing evaluation methods and tools; 2) implementing the teaching plan; 3) collecting evaluations and feedback; and 4) deciding whether and how to revise the curriculum according to evaluations.

\section{MDDE Curriculum Being Developed}

In the second cycle of DBR, typical professional tasks of four key roles in different professional development period are recognized (as shown in Table 4). According to the target group profile, our target students are on-the-job practitioners in DE systems who have passed the stage of novice or New Hand. Hence the MDDE curriculum will adopt professional tasks from Stage 2 to stage 4: i.e., Independent Staff, Team Leader, and Department Manager.

Since our target students have their own existing roles or targeted roles in practice, the professional courses are organized under four theme headings, with each theme relating to a key role in practice. A student may study the courses according to his/ her existing or targeted role. The courses are sequenced by the professional development stages. Three courses, coded as C01, $\mathrm{C02}$, and C03, stand for common professional courses, which are recognized as common professional tasks for the four key roles. 
Table 4

The MDDE Curriculum

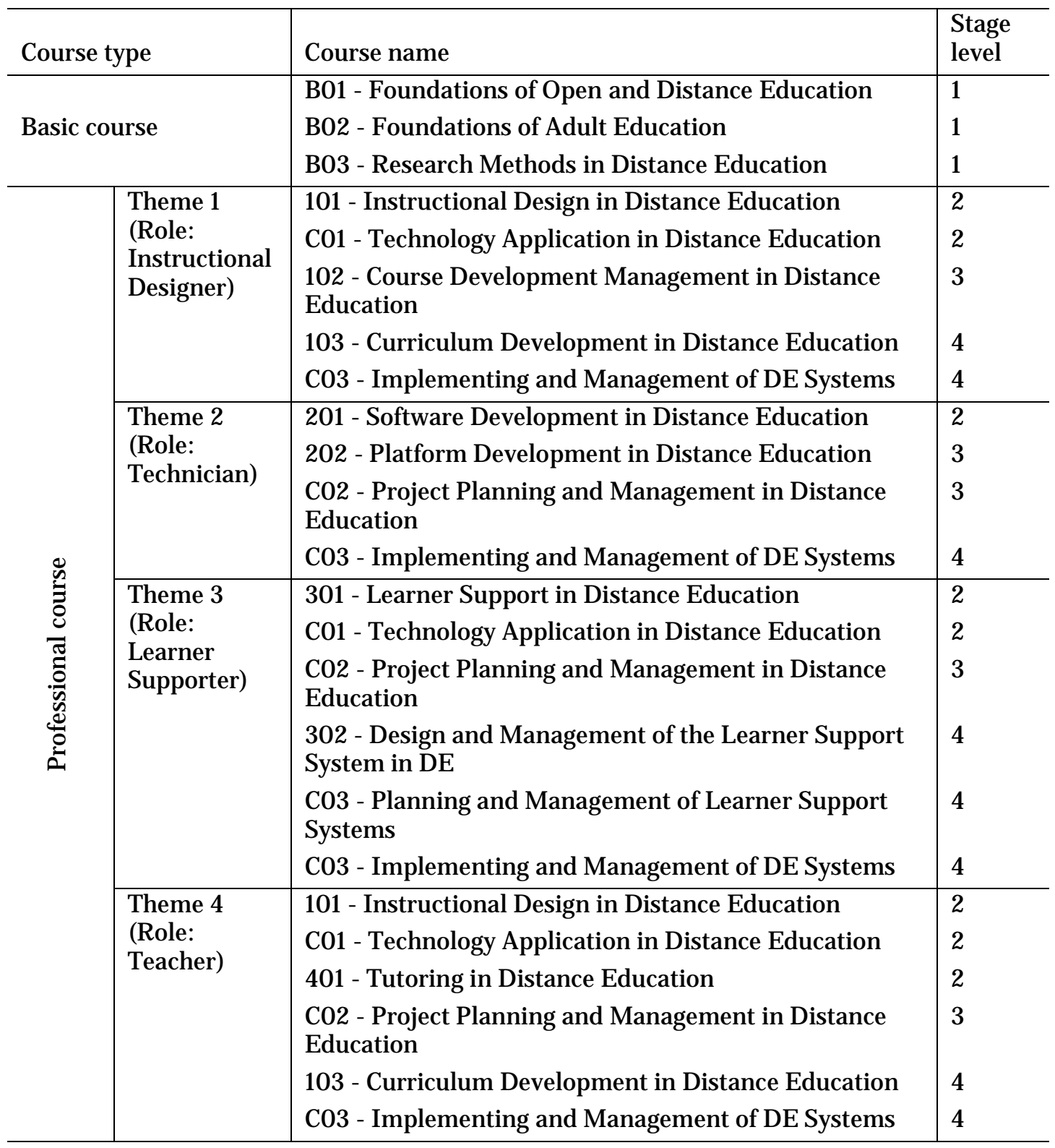

\section{Conclusions}

This study originated in the desire of developing a competency-based curriculum for MDDE and exploring an approach of competency-based curriculum development for distance education 
institutions. Through two iterations of DBR, this study has reached the two-fold purposes. The DECDA model is derived from the PTD method but some significant revisions are made to meet the needs of ODL. Research participants identified that the revised PTD approach gave a better and easier way to integrate the knowledge and the practice, compared with the Delphi method and the DACUM method. The revised PTD approach has four features. 1) Reflection on professional practice. Many researchers emphasized the use of reflection on professional practice to grasp the tacit workplace experience and knowledge (Walsh, 2008; Hegarty \& Kelly, 2011). In the revised PTD approach, reflection of experts plays an important role and helps to recognize the professional development route and critical professional tasks. 2) Professional-task-based learning. The PTD approach is task-oriented and task-based learning is the core strategy of the curriculum. Some other researchers have also agreed that task-based learning is a suitable strategy for adult learners since learning could be more motivated and more individualized for adult learners via task-based learning (Husband and Todd, 2014). 3) Learner analysis. Learner analysis is not taken into account when the traditional PTD approach is used in the fields of vocational education and traditional higher education. However, in the revised PTD approach for distance education, the characteristics of adult learners should be considered and learner analysis helps the curriculum to better fit the target learners. 4) Professional development route-map of key roles. While the traditional PTD approach is only suitable for single-role professions (Zhao, 2009), the revised PTD approach is now suitable for both single-role and multi-role professions after adopting the concept of 'key roles' which has been widely used in role-oriented development. A professional development route-map would be drawn for each key role, including the development stages, duties, critical professional tasks and competency requirements. The clear professional route-map makes it easier to define different competency requirements for different program levels/types and to progress from one type of program to another, and hence may help to answer some researchers' doubt of 'how to make the curriculum developmental' (Cate \& Scheele, 2007; Tanner, 2001).

As an exploration of developing a competency-based curriculum for MDDE by means of taskoriented development, the findings of this study contribute to knowledge and research literatures on both the MDDE curriculum development and the curriculum development methods in ODL. The MDDE curriculum developed in this study is not only suitable for degree education but also suitable for certificate training. The DECDA model provides a professional-task-oriented curriculum development approach which is more feasible for distance education institutions.

Although DBR is an appropriate methodology for this study, this paper only introduced the first 2 iterative cycles of DBR. A third cycle of DBR should be taken in future research in which the effectiveness of the MDDE curriculum needs to be evaluated by all the stakeholders after a whole period of application and it might take another 3 to 4 years. Further researches should also be done to apply and refine the DECDA model in other programs in ODL.

This work is licensed under a Creative Commons Attribution 4.0 International License. 


\section{References}

Achtenhagen, F., \& Grubb, N.W. (2001). Vocational and occupational education: pedagogical complexity, institutional diversity. In Richardson, V. (Ed.), Handbook of research on teaching (pp. 604- 639), Washington: American Educational Research Association.

Ally, M., \& Coldeway, D.O. (1999). Establishing competencies and curricula for the distance education expert at the master's level. J ournal of Distance Education, Vol 14, No 1, pp.7588.

Anderson, A. A. (1994). Vocational education and industry training in Australia. Education \& Training, 36(2), 31.

Anderson, G. (1994). A proactive model for training needs analysis. J ournal of European Industrial Training, 18(3), 23.

Anderson, T., \& Shattuck, J . (2012). Design-based research: A decade of progress in education research? Educational Researcher, 41(1), pp. 16-25.

Boreham, N. (2002a). Work process knowledge, curriculum control and the work-based route to vocational qualifications. British J ournal of Educational Studies, 50, pp. 225-237.

Boreham, N. (2002b). Work process knowledge in technological and organizational development. In Boreham, N., Samurcay, R. \& Fisher, M. (Eds.) Work process knowledge. London: Routledge, pp. 1-14.

Boreham, N. (2004). Orienting the work-based curriculum towards work process knowledge: A rationale and a German case study. Studies in Continuing Education, Vol. 26, No. 2, July 2004.

Boreham, N., \&Lammont, N. (2000). Work process knowledge in technological and organizational development. Final report of Project SOE1-CT97-1074 of the EU Targeted Socio-Economic Research Programme (Brussels, European Commission, Directorate General for Research). Available online at http:// www.cordis.lu/improving/ socioeconomic/publications.htm

Cate, O., \& Scheele, F. (2007). Competency-based postgraduate training: Can we bridge the gap between theory and clinical practice? Academic Medicine, 82(6), pp. 542-547.

Chen, L., \& Li, S. (2004). Research on distance education professionals' competency model in China. China Educational Technology, 2004(3), pp. 62-68. 
Coll, R. K., Taylor, N., \& Nathan, S. (2003). Using work-based learning to develop education for sustainability: a proposal. J ournal of Vocational Education and Training, Vol 55, No 2, pp. 169-181.

Egan, T. M., \&Adkere, M. (2005). Clarifying distance education roles and competencies: exploring similarities and differences between professional and student-practitioner perspectives. American J ournal of Distance Education, Vol 19, No. 2, pp. 87-103.

Frank, J . R., Snell, L.S., Cate, O. ten, Homboe, E. S., Carraccio, C., Swing, S. R., \& Harris, K. A. (2010). Competency-based medical education: theory to practice. Mecdical Teacher, 32, pp. 638-645.

Harden, R. M., Uudlaw, J . M., Ker, J . S., \& Mitchell, H. E. (1996). AMEE medical education guide no. 7.: Task-based learning: An educational strategy for undergraduate postgraduate and continuing medical education, part 1. Medical Teacher, 18(1), 7-13.

Hatcher, R. L., Fouad, N. A., Campbell, L. F., McCutcheon, S. R., Grus, C. L., \& Leahy, K. L. (2013). Competency-based education for professional psychology: Moving from concept to practice. Training and Education in Professional Psychology, 7(4), 225.

Hegarty, P., Kelly, H. A., \&Walsh, A. (2011). Reflection in a workplace qualification: Challenges and benefits. Journal of Workplace Learning, 23(8), pp.531-540.

Heusden, M. R. (2004). The challenge of developing a competence-oriented curriculum: an integrative framework. Library Review, Volume 53, Number 2, 2004, pp.98-103.

Husband, A. K., \&Todd, A. (2014). Integrating science and practice in pharmacy curricula. American J ournal of Pharmaceutical Education, 78(3), pp.1-8.

J ohnson, D. W., \&J ohnson, F. P. (1994). J oining together: Group theory and and group skills. Boston: Allyn and Bacon.

Kang, H., Son, H., Lim, N., Cho, K., Kwon, S., Yi, Y., Park, Y., Lee, E., Kim, J., Han, H., Baik, J ., \& J eong, Y. (2012). job analysis of clinical research coordinators using the DACUM Process. J ournal of Korean Academy of Nursing, 42(7), pp.1027-1038.

Linton, R.H., Nutsch, A., McSwane, D, McSwane, D., Kastner, J ., Bhatt, T., Hodge, S., Getty, K. Maier, D., Kastner, C., Chaturvedi, A., \&Woodley, C. (2011). Use of a stakeholder-driven DACUM process to define knowledge areas for food protection and defense. J ournal of Homeland Security and Emergency Management, 2011, 8(2).

McKenney, S., \&Reeves, T. (2013). Systematic review of design-based research progress: Is a little knowledge a dangerous thing? Educational Researcher, 42(2), pp. 97-100.

This work is licensed under a Creative Commons Attribution 4.0 International License. 
Mndebele, C. B. S. (1997). Developing a competence-based teacher education programme in Swaziland. Education \& Training, 39(6), 237-241.

Mulder, M. (2004). Education, competence and performance: on training and development in the agri-food complex, in augural address. Wageningen: Wageningen University.

O'Halloran, D. (2001). Task-based learning: a way of promoting transferable skills in the curriculum. J ournal of Vocational Education and Training, Vol 53, No 1, 2001, pp. 101119

Percoco, T. A. (1998). Said another way: Is the ADN graduate prepared to practice in community settings? Nursing Forum, 33(3), 23-8.

Plomp, T. (2007). Educational design research: An introduction. An introduction to educational design research, 9.

Powell, D.E. (2011). Introduction to the special education issue. Human Pathology, 2011(42), pp. 761-762.

Rice, K. (2009). Priorities in K-12 distance education: A Delphi study examining multiple perspectives on policy, practice, and research. Educational Technology \& Society, 12(3), pp.163- 177.

Schell, K. A. (2006). A Delphi study of innovative teaching in baccalaureate nursing education. J ournal of Nursing Education, 45(11), pp.439-448.

Sherrill, W., \& Keels-Williams, F. (2005). Mapping competencies for the multiskilled heath care professional: An allied health curriculum reform project. J ournal of Allied Health, 34(4). Pp.185-191.

Teras, H., \& Herrington, J . (2014). Neither the frying pan nor the fire: in search of a balanced authentic e-learning design through an educational design research process. The International Review of Research in Open and Distance Learning, 15(2). pp. 232-253.

Thach, E. (1994). Perceptions of distance education experts regarding the roles, outputs and competencies needed in the field of distance education. Ph.D. diss.. Texas A \& M University, College Station.

Thach, E. C, \& Murphy, K. L. (1995). Competencies for Distance Education Professionals. Educational Technology Research and Development, Vol 43, No.1, pp. 57-79.

The Design-Based Research Collective. (2003). Design-based research: an emerging paradigm for educational inquiry. Educational Researcher, 32(1), pp. 5-8. 
Velde, C. (1999). An alternative conception of competence: implications for vocational education. J ournal of Vocational Education and Training, 51(3), 437-447.

Walsh, A. (2008). What is distinctive about work-based knowledge and learning?. In York, M. (Ed.), Workforce development: connections, frameworks and processes. Higher Education Academy.

Walsh, A. (2009). Modes of reflection: is it possible to use both individual and collective reflection to reconcile the 'three party knowledge interests' in workplace learning? European J ournal of Education, Vol. 44 No. 2, pp. 385-398.

Williams, P. (2003). Making informed decisions about staffing and training: Roles and competencies for distance education programs in higher education. Online J ournal of Distance Learning Administration, Vol 3, No 2.

Williams, P. E. (2003). Roles and competencies for distance education programs in higher education institutions. The American J ournal of Distance Education, 17(1), 45-57.

Xu, G. (2009). A handbook for project-based course development in VET. Shanghai: East China Normal University Press.

Zhao, Z. (2009). A handbook for curricula development in VET. Beijing: Tsinghua University Press.

Ziglio, E. (1996). The Delphi Method and its contribution to decision-making. In M. Alder \&E. Ziglio (Eds.), Gazing into the oracle: The Delphi Method and its application to social policy and public health (pp. 3- 33). Bristol, PA: J essica Kingsley.

(C) Feng, Lu, and Yao

\section{Athabasca University $\mathbf{I}$}

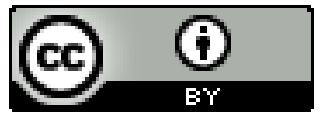

This work is licensed under a Creative Commons Attribution 4.0 International License. 